\title{
Multi-vector activity in the introduction of integrated administration of environmentally safe nature resources use
}

\author{
Nataliia Kovshun ${ }^{1, *}$, Valentyna Kostrychenko ${ }^{1}$, Kateryna Semeniuk ${ }^{1}$, Liliya Filipishyna ${ }^{2}$, \\ and Liudmyla Antonova ${ }^{3}$ \\ ${ }^{1}$ National University of Water and Environmental Engineering, 11 Soborna str., 33028 Rivne, \\ Ukraine \\ ${ }^{2}$ Pervomaisk branch of the National University of Shipbuilding named after Admiral Makarov 107 \\ Odeska St., 55200 Pervomaisk, Ukraine \\ ${ }^{3}$ Petro Mohyla Black Sea National University, 68 Desantniki 10 str., 5400 Mykolaiv, Ukraine
}

\begin{abstract}
The purpose of the article is to build a multi-vector structure of integrated governing of environmentally safe nature resources use according to the principles of a circular economy approach. Based on the the method of mode indicators and the method of fuzzy logic, the index of environmental safety of nature management has been determined. The interpretation of the essence of integrated administration of environmentally safe nature management is given. The organizational and economic mechanism and its implementation has been displayed. The mechanism of integral management as a set of appropriate measures is considered. A multi-vectoral structure is built, which provides for the formation of a system of mechanisms with adequate levers and tools. The providing, adaptive, functional, effective-target subsystem is characterized. The indicators of environmental, economic and social efficiency are determined, which are targeted guidelines when implementing integrated management. The requirements of a systematic approach for a comprehensive implementation of integrated management of natural resource potential are taken into account.
\end{abstract}

\section{Introduction}

Despite the special acuteness of environmental problems, the paradigm of environmentally safe development has not yet become sufficient distribution in Ukraine, and at international levels, legal acts have not been adequately reflected in institutional development, state policy, national programs, and practice. Therefore, the strategic goal of forming and implementing the state ecological policy of Ukraine in modern conditions should be stabilized and improving the state of the environment through the integration of state environmental policy in the socio-economic processes of development of Ukraine.

${ }^{*}$ Corresponding author: n.e.kovshun@nuwm.edu.ua 
The achievement of such goals correlates with the process of forming a circular economy as a high-tech part of the economy, and requires the introduction of integrated management of environmentally safe nature management, taking into account its multi-vector.

\section{Analysis of recent approaches and publications}

The introduction of the principles of a circular economy is now carried out almost around the world in various sectors of the economy. Currently, the value frames and principles of design, implementation, and evaluation of the circular economy [1] are offered.

It deserves special attention to the proposal for the allocation of operational principles that combine the theoretical goals of the circular economy within the framework of sustainable development with practical strategies for its implementation [2]. Different theories that develop and complement each other have been developed to solve environmental problems of economic activity. The goals of sustainable development are subordinated to the provisions of the green economy, the study of aqueous trace, etc. But there are always interdisciplinary approaches that combine clean technologies, modeling of relevant processes, monitoring, and management systems [3].

In the course of the implementation of the circular economy, there are issues that require a solution from both the theoretical and practical points of view. It should be taken into account that there are objective differences in the principles of eco-oriented management between different spheres of production [4]. Studies indicate that this requires the development of relevant strategies not only in the field of production (sources of pollution) but also in the field of interagency cooperation, implementation of educational programs, constructing the relevant business processes, and integrated management [5]. In turn, integrated management is introduced at different levels. It is expedient to use it throughout the chain of business models of circular economics and designing products, planning, production control, logistics, etc. That is, the concept of integrated management is used to create a model of a product life cycle when implementing a circular economy [6]. Particular attention needs to assess the safety of production based on integrated indicators, taking into account interconnected and interrelated economic and environmental components [7]. In this study, a multi-vector structure of integrated management is based on environmentally safe nature management (ESM).

\section{Results}

According to the results of the analysis of the ESM level in Ukraine (Table 1), problems caused by the unsatisfactory state of use of natural conditions and resources are revealed.

Table 1. State indicators of ESM in Ukraine.

\begin{tabular}{|l|c|c|c|c|c|}
\hline \multicolumn{1}{|c|}{ Indicators } & $\begin{array}{c}\text { Units of } \\
\text { measure } \\
\text { ment }\end{array}$ & 2010 & 2015 & 2019 & $\begin{array}{c}\text { Absolute } \\
\text { deviation 2019 } \\
\text { from 2015 }\end{array}$ \\
\hline $\begin{array}{l}\text { Emissions of pollutant } \\
\text { substances into atmospheric air } \\
\text { from stationary and mobile } \\
\text { sources of pollution }\end{array}$ & ths. t. & 6678.0 & 4521.3 & 4108.3 & -413 \\
\hline $\begin{array}{l}\text { General drainage-intelligence } \\
\text { reciprocal waters }\end{array}$ & $\mathrm{mln. \textrm {m } ^ { 3 } .}$ & 1744 & 875 & 737 & -138 \\
\hline Volume of wastes & $\mathrm{mln} \mathrm{t.}$ & 425.9 & 312.3 & 441.5 & 129.2 \\
\hline The volume of utilized waste & $\mathrm{mln} \mathrm{t}$. & 153.8 & 92.4 & 108.0 & 15.6 \\
\hline
\end{tabular}


The main problem is defined by pollution, industrial waste production through obsolete fixed assets; deterioration of hygienic and sanitary and epidemiological conditions of human life; low productivity of treatment facilities, reduction of biological performance.

The main reasons for these problems in Ukraine were the following: failure to take measures to reduce pollution volumes to the regulatory level within the established time frame; imperfection of existing organizational and legal forms of management and Budget and tax regulation; lack of investment. Based on the application of the method of standartization of indicators formula and the method of Fuzzy Logic formula the index of environmental safety of nature management for the regions of Ukraine is determined and their classification is carried out according to this indicator.

According to the first approach, the index ESM IB is calculated by the ratio:

$$
I B_{i}=1-\frac{d_{i s}}{d_{c}+2 s_{d}} .
$$

where, $\quad d_{i s}=\sqrt{\left(z_{1 i}-z_{1 s}\right)^{2}+\left(z_{2 i}-z_{2 s}\right)^{2}+\ldots+\left(z_{k i}-z_{k s}\right)^{2}}$ - distance from the object $\left\langle Z_{i}\right\rangle=\left(z_{1 i}, z_{2 i}, \ldots, z_{k i}\right)$ to the reference object $\left\langle Z_{s}\right\rangle=\left(z_{1 s}, z_{2 s}, \ldots, z_{k s}\right)$;

$z_{i}=\frac{\bar{x}_{i}-x_{i}}{s_{x i}}$ is standardized value $i$-th indicator-destimulator;

$\bar{x}_{i}$ - average sample value $i$ - th of the indicator;

$d_{c}-$ average distance value for all system objects to the reference object ;

$S_{d}-$ mean square deviation for a set of distances.

The Fuzzy Logic method is based on the concept of the affiliation function, which is used to translate the value of input numerical variables into a unclear linguistic form of the phasification process. In research is used P-similar function of belonging $f_{n}$, what is the multiplication of two sigmoid functions?

$$
f_{\Pi}(x ; a, b, c, d)=f_{1}(x ; a, b) \cdot f_{2}(x ; c, d)
$$

where, $x$ - the value of the input variable; $a, b, c, d$ - some numeric parameters;

$$
f_{1}(x ; a, b)=\frac{1}{1+e^{-a(x-b)}} ; \quad f_{2}(x ; c, d)=\frac{1}{1+e^{-c(x-d)}}
$$

The fuzzy logical inference system is based on the Mamdani algorithm. The ESM index is obtained by defasifying the aggregated output of the logical output system.

Calculations have shown that the values of the ESM indices obtained using the two approaches are quite close. For most regions of Ukraine, this indicator is at risk, threat or danger. This proves the urgent need to improve the ESM processes, which is due to the lack of integration of the efforts of the public administration system and communities in environmental protection issues, the presence of uncertainties on the part of ministries and departments in the formation and implementation of a sustainable development strategy and the state policy of nature management.

The construction of the integrated ESM management system is based on a set of principles for the protection, rational use and reproduction of each type of natural conditions and resources. Integrated use management is a planned, systematic and comprehensive activity of management entities aimed at the environmentally safe use of natural conditions and resources. The success of ESM management is determined by a positive increase in socio-economic development indicators while reducing environmental pollution [8-12]. This assessment is based on integrated indicators taking into account interdependent and interrelated economic and environmental components [13-16]. 
The methodological approach to integrated ESM is formed based on the idea of sufficiency and high quality of natural potential components for ensuring and developing ESM components. This approach ttook into account the existing developments in creating optimization systems based on the principles of circular economics based on a multipurpose approach that covers aspects of economic and environmental sustainability within the same framework [17-23].

We consider a set of measures aimed at solving issues of protection, environmentally safe use and reproduction of Natural Resource Potential, which is characterized by the presence of special interaction links, to be a mechanism for integrated management of ESM. The mechanism of integrated management of the ESM should include the following subsystems: providing, adaptive, functional, effective-target (Fig.1).

\begin{tabular}{|c|c|c|c|}
\hline \multicolumn{4}{|c|}{ Subsystems of the integrated control mechanism ESM } \\
\hline providing & adaptation & functional & effective-target \\
\hline \multirow{2}{*}{ Regulatory } & \multirow{2}{*}{$\begin{array}{l}\text { Monitoring of } \\
\text { natural conditions and } \\
\text { resources }\end{array}$} & Strategy & \multirow{3}{*}{$\begin{array}{l}\text { Environmental } \\
\text { efficiency of using } \\
\text { natural resource } \\
\text { potential }\end{array}$} \\
\hline & & Planning & \\
\hline Information support & $\begin{array}{c}\text { Scientific and } \\
\text { methodical base }\end{array}$ & Motivation & \\
\hline \multirow{2}{*}{$\begin{array}{l}\text { Administrative and } \\
\text { organizational } \\
\text { support }\end{array}$} & \multirow{2}{*}{$\begin{array}{l}\text { Ecological and } \\
\text { economic analysis }\end{array}$} & Organization & \\
\hline & & Regulation & \multirow{2}{*}{$\begin{array}{l}\text { Social efficiency of } \\
\text { using natural resource } \\
\text { potential }\end{array}$} \\
\hline \multirow[t]{3}{*}{ Financial support } & $\begin{array}{l}\text { Ecological and } \\
\text { economic security }\end{array}$ & Controlling & \\
\hline & Ecological culture & & \multirow[b]{2}{*}{$\begin{array}{l}\text { Economic efficiency } \\
\text { of using natural } \\
\text { resource potential }\end{array}$} \\
\hline & $\begin{array}{l}\text { Economic, Legal and } \\
\text { Socio-Environmental } \\
\text { Responsibility } \\
\text { Education }\end{array}$ & & \\
\hline
\end{tabular}

Fig. 1. Component subsystems of the integrated control mechanism of the ESM.

Ecological and socio-economic aspects of environmentally friendly use and reproduction of natural resource potential require effective functioning of the providing subsystem in the integrated management mechanism. Such a subsystem involves the compulsory presence of normative and legal, information, administrative and organizational, and financial support.

The purpose of the adaptation subsystem is the formation of "flexibility of the mechanism" in accordance with the requirements of the environment in environmentally friendly development, which is impossible without an effective mechanism of interaction between the state, legislative and executive authorities, the public.

The functional subsystem includes strategy, planning, motivation, organization, regulation, and control that act as basic functions of integrated management of nature management. The strengths and weaknesses, threats, and opportunities associated with the use of natural conditions and resources are evaluated. The system of factors and guys also affects the processes of ensuring environmentally friendly development [24-25]. 
Using a strategy, a long-term plan is developed to ensure the purpose of implementing the purpose, tasks, and achievement of goals, with the help of planning, priorities, and directions of strategy execution are determined, as well as tactical and operational actions, to achieve the definite goal.

The effective target subsystem outlines goals (tasks). Its components determine the ecological, social, and economic efficiency of the use of natural resource potential. Environmental efficiency is determined by a decrease in the volume of environmental pollution.

Indicators of ecological efficiency are as follows: the coefficient of ecological efficiency (the ratio of actual indicators of environmental efficiency of environmental measures to scientifically substantiated standards); structure and efficiency of capital investments for the reproduction of natural resource potential; dynamics of state and quality of natural resources; dynamics of indicators of negative anthropogenic influence (emissions into the atmosphere, discharges in the reservoirs, waste placement, etc.); dynamics of introducing progressive technologies; the pace of reproduction of natural resource potential; structure of capital and current expenses on environmental measures.

Social efficiency manifests itself in improving the quality of life of the population. Indicators of social efficiency are coefficient of social efficiency (the ratio of normative indicators characterizing the level of individual social services to actual); the pace of productivity of living labor; saving living labor; dynamics of population incidence; efficiency and possibility of using free time working; level of satisfaction of material and spiritual needs of employees; Dynamics of indicators of living standards (education, culture, health care, social security, residential and municipal services, transport service); Structure of obtaining and using incomes.

Economic efficiency is calculated as the ratio of the resulting effect to the entire amount of capital investments that provided it.

Indicators of economic efficiency are as follows: the actual level of satisfaction of the needs of the population in products; growth of production of basic types of products per capita; the growth rates of national income; rates of growth of labor productivity and production of environmentally friendly and environmentally friendly products on the average annual working; structure and rates of growth resource; funds word (production of products to the value unit of the main production assets); payback of the cost unit of production costs; material return (production of products at the cost unit of material expenditure); coefficient of efficiency of material investments; the general level of product quality, which corresponds to world standards and EU standards in the total amount of products produced per-unit costs of living and arched labor; reduction of production costs; the share of ecologically safe products produced at the expense of intensive factors; the pace of increasing the technical level of production.

The integrated control system of the ESM covers the following components: environmental, social, economic, institutional, informational, political, and legal, etc. In the process of its implementation, it is necessary to introduce such effective levers and instruments that provide protection, as well as environmentally safe use of natural conditions and resources. For example, economic stimulation of owners and users of natural resource potential, improving environmental insurance to ensure damages in case of harm to natural resource potential and subsequently minimize the risks of environmentally hazardous events [10].

Integrated ESM is based on the use of managerial actions for the formation and support of key factors that affect the protection, environmentally safe use of natural resource potential. Natural resource potential is not just a set of certain types of resources, but a system of interconnected optimal quantitative and qualitative resource proportions. 
In this communication, the system approach means that integrated governance should not focus only and on one potential element, and to solve problems with the environmentally safe use of natural resource potential is comprehensive as a single whole, taking into account the relationship between all its elements.

Properties of the integrated ESM system are related to system functions (synergies, multiplicity, purposefulness, realism); structure of the system (structural, complexity, not additivity, hierarchy, proportionality); Interaction with the medium (stability, dynamism, compatibility, adaptability, time).

We defined integrated ESM as a set of mechanisms and instruments aimed at coordinating and regulating the use of natural conditions and resources, stimulating environmental activities, and ensuring economic responsibility for deteriorating the environmental state of natural resource potential.

The purpose of the formation and effectiveness of the organizational and economic mechanism of integrated management of the EBA is the creation of organizational and economic conditions for ensuring sustainable development of the region, the country. The organizational component of the integrated ESM mechanism includes organizational methods of management, organization of achievement of intended goals, regulation of activity, ecological and economic analysis (audit), monitoring of natural resources, as well as administrative, organizational, and social and psychological aspects. The organizational component involves the implementation of such functions as a choice and substantiation of the methods of organization and regulation of the ESM, as well as the introduction of progressive forms of organization of this activity and an effective system of motivation, protection, environmentally safe use and reproduction of natural resource potential. The economic component of the integrated ESM management mechanism provides for financial provision of protection processes, environmentally safe use of natural resource potential (includes lending and investment and innovation activity, pricing in the field of ecosystem goods and services, stimulating ESM, insurance of ecological and economic risks, ecological and economic responsibility), an assessment of the effectiveness of the use of natural resource potential.

Economic levers in the integrated ESM management system include economic stimulation of environmental activities and economic responsibility for violation of natural resource potential.

Economic stimulation of environmentally safe activities includes: reimbursement of the cost of owners of natural resources on their reproduction; providing tax privileges to natural resources owners, as well as financial and credit support for ESM development.

To economic responsibility for violation of the established protection regimes, noncompliance with the requirements of environmentally friendly use and reproduction of natural resource potential include:

- penalties for the use of components of natural resource potential are not intended, as well as for violation of environmental legislation;

- compensation for losses by the state for non-environmentally friendly nature use;

- Petty for the untimely introduction of environmental payments.

Components of the organizational and economic mechanism, performing certain functions, complement each other and intermittent in management. The organizational and economic mechanism of integrated ESM includes environmental tools, which include standardization, certification, examination, audit, marketing, etc.

Stages of organizational and managerial actions for ensuring protection, environmentally safe use, and reproduction of natural resource potential includes an analytical unit, blocks of preparation, and implementation of measures for the implementation of control. 


\section{Conclusions}

The basis for the development and implementation of measures for protection, the ESM, and the reproduction of natural resource potential should be assigned the following determinants: defining the integrity and integrity of the system in preserved natural conditions and resources; Differentiated approach to all components of environmentally friendly nature use, specificity and features of which determine the choice of strategy of relevant actions, etc.

Priority tasks for introducing an integrated ESM are formulated taking into account its multivocality and are reduced to the following: detection and systematization of the components of the ESM management; monitoring of components of natural resource potential; providing the necessary regime of management of natural resource potential and its use; Inclusion of measures for protection ESM in the main strategic programs of socioeconomic development of the region and state in accordance with EU requirements.

\section{References}

1. Urbinati, A., Chiaroni, D., \& Chiesa, V. (2017). Towards a new taxonomy of circular economy business models. Journal of Cleaner Production, 168, 487-498.

2. Suárez-Eiroa, B., Fernández, E., Méndez-Martínez, G., \& Soto-Oñate, D. (2019). Operational principles of circular economy for sustainable development: Linking theory and practice. Journal of cleaner production, 214, 952-961.

3. Van Fan, Y., Lee, C. T., Lim, J. S., Klemeš, J. J., \& Le, P. T. K. (2019). Crossdisciplinary approaches towards smart, resilient and sustainable circular economy. Journal of cleaner production, 232, 1482-1491.

4. Zhu, Q., Geng, Y., \& Lai, K. H. (2010). Circular economy practices among Chinese manufacturers varying in environmental-oriented supply chain cooperation and the performance implications. Journal of Environmental Management, 91(6), 1324-1331.

5. de Sousa Jabbour, A. B. L., Luiz, J. V. R., Luiz, O. R., Jabbour, C. J. C., Ndubisi, N. O., de Oliveira, J. H. C., \& Junior, F. H. (2019). Circular economy business models and operations management. Journal of cleaner production, 235, 1525-1539

6. Gómez, A. M. M., González, F. A., \& Bárcena, M. M. (2018). Smart eco-industrial parks: A circular economy implementation based on industrial metabolism. Resources, conservation and recycling, 135, 58-69.

7. Cherchyk, L., Shershun, M., Khumarova, N., Mykytyn, T., \& Cherchyk, A. (2019). Assessment of forest enterprises' performance: integrating economic security and ecological impact. Entrepreneurship and sustainability issues, 6(4), 1784.

8. Cherchyk, L., Shershun, M., Khumarova, N., Mykytyn, T., \& Cherchyk, A. (2019). Assessment of forest enterprises' performance: integrating economic security and ecological impact. Entrepreneurship and sustainability issues, 6(4), 1784.

9. Mikhno, I., Koval, V., Shvets, G., Garmatiuk, O., \& Tamošiūnienė, R. (2021). Green Economy in Sustainable Development and Improvement of Resource Efficiency. Central European Business Review, 10(1), 99-113.

10. Balaman, Ş. Y., Wright, D. G., Scott, J., \& Matopoulos, A. (2018). Network design and technology management for waste to energy production: An integrated optimization framework under the principles of circular economy. Energy, 143, 911-933. 
11. Nazarova, K., Mysiuk, V., Gordopolov, V., Koval, V., \& Danilevičienė, I. (2020). Preventional audit: implementation of SOX control to prevent fraud. Business: Theory and Practice, 21(1), 293-301.

12. Dankeieva, O., Solomianiuk, N., Strashynska, L., Fiedotova, N., Soloviova, Y., \& Koval, V. (2021). Application of Cognitive Modelling for Operation Improvement of Retail Chain Management System. TEM Journal, 10(1), 358-367.

13. Yakymchuk, A. Y., Navrotskyi, R. L., \& Kovshun, N. E. (2017). Natural resources potential as innovative and investment development prospect. Scientific bulletin of Polissia, 1(3 (11)), 179-186.

14. Arsawan, I.W.E., Koval, V., Rajiani, I., Rustiarini, N.W., Supartha, W.G. and Suryantini, N.P.S. (2020). Leveraging knowledge sharing and innovation culture into SMEs sustainable competitive advantage. International Journal of Productivity and Performance Management (in press).

15. Koval, V., Kovshun, N., Plekhanova, O., Kvitka, S., \& Haran, O. (2019). The role of interactive marketing in agricultural investment attraction. 19th International Multidisciplinary Scientific GeoConference SGEM 2019, 19(5.3), 877-884.

16. Kvasha, S., Pankratova, L., Koval, V., \& Tamošiūnienė, R. (2019). Illicit financial flows in export operations with agricultural products. Intelellectual Economics, 13(2), 195-209.

17. Vdovenko, N., Deriy, J., Seliverstova, L., \& Kurmaiev, P. (2019). Formation of the information economy: Organizational and financial aspects. International Journal of Supply Chain Management, 8(4), 956-961.

18. Vdovenko, N., Baidala, V., Burlaka, N., \& Diuk, A. (2018). Management mechanism of agrarian economic system: composition, functions and factors of development in Ukraine. Problems and Perspectives in Management, 16(2), 179-189.

19. Filipishyna, L., Bessonova, S., Venckeviciute, G. (2018). Integral assessment of developmental stability: cases of Lithuania and Ukraine. Entrepreneurship and Sustainability Issues, 6(1), 87-99.

20. Vdovenko, N. (2015). Mechanisms of regulatory policy application in agriculture. Economic Annals-XXI, (5-6), 53-56.

21. Mannekote, J. K., Kailas, S. V., Venkatesh, K., \& Kathyayini, N. (2018). Environmentally friendly functional fluids from renewable and sustainable sources-A review. Renewable and sustainable energy reviews, 81, 1787-1801.

22. Arsawan, I. W. E., Sanjaya, I. B., Putra, I. K. M., \& Sukarta, I. W. (2018). The effect of expatriate knowledge transfer on subsidiaries' performance: a moderating role of absorptive capacity. In Journal of Physics: Conference Series, 953(1), 012082.

23. Yankovyi, O., Goncharov, Yu., Koval, V., \& Lositska, T. (2019). Optimization of the capital-labor ratio on the basis of production functions in the economic model of production. Naukovyi Visnyk Natsionalnoho Hirnychoho Universytetu, 4, 134-140.

24. Khadka, B. (2020). Rammed earth, as a sustainable and structurally safe green building: a housing solution in the era of global warming and climate change. Asian Journal of Civil Engineering, 21(1), 119-136.

25. Grădinaru, C. M., Şerbănoiu, A. A., Babor, D. T., Sârbu, G. C., Petrescu-Mag, I. V., \& Grădinaru, A. C. (2019). When agricultural waste transforms into an environmentally friendly material: The case of green concrete as alternative to natural resources depletion. Journal of Agricultural and Environmental Ethics, 32(1), 77-93. 